\title{
Special Care Dentistry Curriculum at The Undergraduate Level : Students' Prespective
}

\author{
Natrah A. Fuad ${ }^{1}$, Jacob John ${ }^{1}$, Wen T. Koh ${ }^{1}$, Shani A. Mani ${ }^{1}$, Wan-Lin S. Lim ${ }^{1}$, Chee \\ S. Wong', Vinod K. Joshi' ${ }^{1}$, Maryani M. Rohani ${ }^{1}$, Samuel Zwetchkenbaum ${ }^{2}$ \\ ${ }^{1}$ Faculty of Dentistry, University of Malaya, 50603 Kuala Lumpur, Malaysia \\ ${ }^{2}$ Rutgers School of Dental Medicine, The State University of New Jersey, Newark, New Jersey, USA \\ Correspondencee-mail to: drjacob@um.edu.my
}

\begin{abstract}
Special needs patients (SNP) have difficulty accessing dental services, partly due to reluctance of dentists to treat them. Objective: We assess didactic and clinical training experiences of final-year dental students and new graduates in managing SNP. Methods: An online questionnaire was sent to 123 final year dental students and new graduates, assessing their experiences and readiness in handling SNP. Results: Majority of the respondents were not confident in attending to SNP. Majority gained knowledge in handling SNP via lectures while more than half had managed patients with complex medical history. Majority mentioned a lack of clinical training to treat SNP as their dental training experience had only been in a dental school clinical setting. Most of the respondents hope their curriculum would include more education to improve clinical skills in managing SNP. Conclusion: Respondents demonstrated minimum training and lack of confidence and skills that might contribute to a lack of preparedness to manage the oral health care needs of SNP. Clinical exposure in managing SNP at the undergraduate level is still inadequate and it needs to be emphasized in the curriculum.
\end{abstract}

Keywords: SNP, special care dentistry, undergraduate curriculum, dental care

\section{INTRODUCTION}

Patients requiring special dental care in Malaysia, as in other parts of the world, have recently become more significant. The United Nations estimated a total of 2.8 million people in Malaysia with disabilities. ${ }^{1}$ In 2010, World Health Organization (WHO) approximated about $15 \%$ of the world's population lives with disabilities with at least $2 \%$ to $4 \%$ living with significant functional disabilities. $^{2}$ The increase in the population of special needs patients (SNP) is probably due to the increase in their life expectancy. ${ }^{3}$ According to WHO data, which was published in 2011, life expectancy in Malaysia is approximately 72 years for males and 76 years for females. ${ }^{4}$ Disabilities not only affect the individuals but also on the people around them such as families and care takers, support systems as well as the delivery of health care services. ${ }^{3}$

People with disabilities as those who have long-term physical, mental, intellectual or sensory impairments, which in interaction with various barriers may hinder their full and effective participation in the society. ${ }^{5}$
In terms of oral health, Commission on Dental Accreditation (CODA) defines special needs patients as individuals 'whose medical, physical, psychological or social situations make it necessary to modify normal dental routines in order to provide dental treatment for that individual. WHO International Classification of Functioning (ICF) model has defined people requiring special dental care as those with disability or active restriction that directly or indirectly affects their oral health. ${ }^{6}$ Special care dentistry (SCD) is defined as the branch of dentistry that provides dental services to patients with physical, medical, developmental or cognitive conditions which limit their ability to receive routine dental care. ${ }^{7}$ People with disabilities have poorer oral health and poorer general health outcomes due to high levels of unmet needs as well as fear and inability to access oral health care services. ${ }^{8-10}$

In order to ensure SNP receive appropriate and adequate oral health care services and to reduce inequalities in oral health, it is very crucial that current dental 
Table 1: Types of classroom-based methods used to teach SCD

\begin{tabular}{lll}
\hline Methods & Yr5 & FYDO \\
\hline Lectures & $62(98.4 \%)$ & $40(97.6 \%)$ \\
Problem Based Learning (PBL) & $48(76.2 \%)$ & $22(53.7 \%)$ \\
Small group discussions & $35(55.6 \%)$ & $16(39.0 \%)$ \\
Videotapes/DVD & $2(3.2 \%)$ & $3(7.3 \%)$ \\
Demonstrations & $36(57.1 \%)$ & $6(14.6 \%)$ \\
Case studies & $45(71.4 \%)$ & $10(32.3 \%)$ \\
\hline
\end{tabular}

Yr5=final year dental student; FYDO=first year dental officer

practitioners and their dental nurses are well equipped to provide dental treatment to SNP. It is also important to educate future oral health care providers to treat SNP by exposing them to SCD at the undergraduate level. CODA stated that 'graduates must be competent in assessing the treatment needs of SNP. ${ }^{11}$ In studies conducted by Waldman and Perlman, they found that most dentists reported a lack of knowledge in providing care to SNP. ${ }^{12}$ It was found that less than $50 \%$ of participating dental school in a survey in the USA required their students to have clinical experience treating SNP. ${ }^{13}$ Due to the reasons mentioned above, majority of the practicing dentists do not have the confidence and willingness to treat special needs patients. The significance of SCD in dental schools in Malaysia is still unclear although the specialty has recently gained its recognition with the inception of three centers providing SCD services.

It is very crucial to provide education on SCD in dental schools at undergraduate level. Therefore, the objectives of this study are to assess the need to include SCD curriculum in the undergraduate level and to provide feedbacks that would help in gauging the interest of SCD among the students.

\section{METHODS}

The study was approved by the Faculty of Dentistry University of Malaya Medical Ethics Committee. A draft of the questionnaire form was designed by the investigators based on a previously administered survey. ${ }^{14}$ The questionnaire was prepared as an E-survey on the Kwik Survey platform. Before being distributed, the questionnaire was sent to all the authors to test its effectiveness. Between January and February 2015, an e-mail with a link to the survey was sent to 123 participants consisting of final year dental students (Yr5) and First Year Dental Officers (FYDO) who just graduated from University of Malaya.

Participants were requested to reply within a month and given constant reminders via Facebook and Whatsapp
Table 2: Clinical settings that helped gain experience in managing SNP

\begin{tabular}{lll}
\hline Clinical settings & Yr5 & FYDO \\
\hline Dental school clinical setting & $55(87.3 \%)$ & $30(73.2 \%)$ \\
Hospital-based dental clinic & $18(28.6 \%)$ & $13(31.7 \%)$ \\
Community rehabilitation center & $25(39.7 \%)$ & $18(43.9 \%)$ \\
Day care center for the disabled & $36(57.1 \%)$ & $16(9.0 \%)$ \\
Old folks home & $18(28.6 \%)$ & $16(9.0 \%)$ \\
None of the above & $0(0 \%)$ & $2(4.9 \%)$ \\
\hline
\end{tabular}

Yr5=final year dental student; FYDO=first year dental officer

messages. The survey basically consisted of classroom based dental education concerning treatments of SNP, clinical education concerning the treatment of SNP, and questions concerning the future professional life with regards to providing care to SNP following the model used by Krause et al. ${ }^{15}$ All responses were anonymous and only people responsible for the data collection had access to the information participants provided. Data were gathered and recorded in Microsoft Excel while analysis was done using SPSS (version 17). ${ }^{16}$

\section{RESULTS}

A total of 104 responses were received (84.6\% response rate) comprising of $63 \mathrm{Yr} 5$ students and 41 FYDO. Majority of respondents in both groups were more likely to be female. Almost all respondents claimed to have been exposed to lectures in SCD while more Yr5 students have been exposed to other methods of teaching-learning like PBL, small group discussions, demonstrations and case studies (Table 1).

In terms of clinical settings that helped in gaining experience in managing SNP (Table 2), $87.3 \%$ of the Yr5 students and $73.2 \%$ of the FYDO respectively claimed that the experience was mainly gained from dental school clinical setting followed by the day care centers for the disabled. Some also claimed that experience was gained from hospital-based dental clinic, community rehabilitation center as well as old folks' homes. Due to their additional experience, FYDOs seem to have managed more SNP during their clinical postings. This is shown in Table 3. More than half of both groups of respondents have experienced managing patients with complex medical history. In addition, majority of FYDOs have experience managing patients with intellectual disability $(65.9 \%)$.

Table 4 provides an overview on the perception of the respondents towards the teaching of SCD at the dental school. Majority of the respondents agree the subject should be included in the curriculum and believe the school is moving in the right direction of equipping 
Table 3: Types of SNP having been managed during clinical posting

\begin{tabular}{lll}
\hline Types of patients & Yr5 & FYDO \\
\hline Physical disabilities & $11(17.4 \%)$ & $15(36.6 \%)$ \\
Sensory impairments & $12(19.0 \%)$ & $13(31.7 \%)$ \\
Intellectual disabilities & $13(20.6 \%)$ & $27(65.9 \%)$ \\
Complex medical history & $33(52.4 \%)$ & $28(68.3 \%)$ \\
Home-bound elderly patients & $10(15.9 \%)$ & $7(17.1 \%)$ \\
Communicable infections & $10(15.9 \%)$ & $23(56.1 \%)$ \\
Socially deprived & $2(3.2 \%)$ & $7(17.1 \%)$ \\
Drug or alcohol abuse problems & $0(0 \%)$ & $5(12.2 \%)$ \\
Adult onset neurological diseases & $7(11.1 \%)$ & $6(14.6 \%)$ \\
Psychopathologies & $13(20.6 \%)$ & $15(36.6 \%)$ \\
\hline
\end{tabular}

Table 4: Perception towards teaching of SCD at dental school

\begin{tabular}{lll}
\hline & Yr5 & FYDO \\
\hline $\begin{array}{l}\text { My classes prepared me well for } 24(38.1 \%) \\
\text { managing SNP }\end{array}$ & $11(26.8 \%)$ \\
$\begin{array}{l}\text { The curriculum should include more } \\
\text { education about managing SNP }\end{array}$ & & \\
$\begin{array}{l}\text { I believe that my dental school has } \\
\text { an honest interest in treating SNP }\end{array}$ & $56(88.9 \%)$ & $31(75.6 \%)$ \\
$\begin{array}{l}\text { The dental education I received for } \\
\text { managing SNP is adequate/sufficient }\end{array}$ & $40(97.6 \%)$ \\
$\begin{array}{l}\text { My clinical skills were adequate for } \\
\text { me to be able to treat SNP }\end{array}$ & $12(29.3 \%)$ \\
\hline
\end{tabular}

Yr5=final year dental student; FYDO=first year dental officer

them with the necessary knowledge. Although less than half the respondents feel that the dental education they received prepared they well to manage SNP, Yr5 students seem to agree more than the FYDOs. However, compared to the FYDOs, majority of Yr5 students feel their clinical skill gained thus far is very inadequate to treat SNP.

The final objective of the study was to assess the respondents' willingness to provide care in the future (Table 5). Regardless of the lack of awareness and knowledge on SCD, respondents showed great interest to manage SNP in the future. Despite the inadequacy of their clinical experience in treating SNP, a large number of respondents, $49.2 \%$ of Yr5 students and $53.7 \%$ of FYDOs believed that they would be able to provide care for their special needs patients. They are aware that providing care for SNP will take more of their time, make themselves as well as the patients more anxious and may not be cost-effective for their practice. However, they are ready to spend extra money to make their practice SNP friendly because it will help them feel a sense of satisfaction to have been able to treat the patient
Table 5: Respondents' willingness to provide dental treatment to SNP in the future

\begin{tabular}{lll}
\hline & Yr5 & FYDO \\
\hline $\begin{array}{l}\text { Providing care would not take too } \\
\text { long }\end{array}$ & $16(25.4 \%)$ & $7(17.1 \%)$ \\
$\begin{array}{l}\text { The care would not make patient } \\
\text { anxious }\end{array}$ & & \\
$\begin{array}{l}\text { I can provide quality care for my } \\
\text { patients }\end{array}$ & $31(49.2 \%)$ & $22(53.7 \%)$ \\
$\begin{array}{l}\text { I am not concerned that my practice } \\
\text { would end up with too many special }\end{array}$ & & \\
needs patients & & \\
$\begin{array}{l}\text { It would not disrupt the organization } \\
\text { of my practice }\end{array}$ & $30(47.6 \%)$ & $22(53.7 \%)$ \\
$\begin{array}{l}\text { I would know how to deal with the } \\
\text { patient's behaviour }\end{array}$ & $40(63.5 \%)$ & $21(51.2 \%)$ \\
$\begin{array}{l}\text { I will be able to communicate } \\
\text { effectively }\end{array}$ & $36(57.1 \%)$ & $23(56.1 \%)$ \\
$\begin{array}{l}\text { It would not make me anxious } \\
\text { It would be safe for me and my team }\end{array}$ & $29(46.0 \%)$ & $22(53.7 \%)$ \\
$\begin{array}{l}\text { The treatment will be cost-effective } \\
\text { for my practice }\end{array}$ & $20(31.7 \%)$ & $16(39.0 \%)$
\end{tabular}

The patient will follow my after- $7(11.1 \%) \quad 13(31.7 \%)$ care instructions

I would rather refer the patient to $26(41.3 \%) \quad 18(43.9 \%)$ a specialist

I feel a sense of satisfaction to be $52(82.5 \%) \quad 32(78.0 \%)$ able to treat the patient

I will spend extra money to make $32(50.8 \%) 26(63.4)$ my practice SNP friendly

Yr5=final year dental student; FYDO=first year dental officer

\section{DISCUSSION}

This web-based or electronic survey is cost effective and it is easy to track the non-responders compared to paper-based surveys. Apart from that, E-surveys are definitely more environment friendly, have less data entry errors and provides quicker access to the response. The response rate is also very encouraging. This is also supported by a study that found the majority of online responders responded after the first invitation and young respondents preferred web-based surveys. ${ }^{17}$ However, one need to make sure the email addresses of the respondents are current and because there is no monetary incentives for the respondents, the survey administrator will need to repeatedly invite those who fail to participate. ${ }^{18}$

Based on the outcome of this study, it is very clear that including SCD at the undergraduate dental curriculum is very important and it is crucial that a dental school graduate knows how to diagnose and assess the treatment needs of SNP. Many patients who currently fall under the remit of special care dentistry could be treated safely in general dental practice. ${ }^{19} \mathrm{The}$ 
traditional curriculum exposes students to managing patients with complex medical history, especially those seeking dental extraction. However, with the introduction of SCD, the students can be exposed to managing a larger cohort of patients that include those with physical disabilities, home-bound elderly, patients with communicable infections, socially deprived patients, patients with drug or alcohol abuse problems, patients with adult onset neurological diseases as well as patients with psychopathologies, provided the dental school has a dedicated, free-standing special needs clinic.

Studies reported that majority of dentists and dental students still lack clinical experience in treating SNP. ${ }^{20}$ A varied, multi dimensional educational experience in SCD at undergraduate level plays an important role in developing students' positive attitude, confidence and willingness to treat SNP later in their practice ${ }^{14}$. These findings are consistent with the findings in our study where many respondents demonstrated reluctance and lack of confidence in treating SNP. Our study also demonstrated that majority of the respondents have never managed certain patient groups like those with communicable infections, sensory impairment, drug or alcohol abuse problems as well as those who are socially deprived. These are SNP who can be treated by any general dental practitioner but due to poor exposure, they tend to develop a stigma towards these patients and avoid treating them.

Based on the results from our study, majority of the respondents will not refuse providing treatment to SNP. However, there seems to be a great variation in the attitude and willingness towards managing SNP among the respondents even though they come from the same dental school. It would be interesting to investigate further the factors determining respondents' attitude towards SNP. This study has also proven that majority of the respondents lack confidence in providing treatment to SNP, leading to a reduction in the number of SNP receiving treatment and inequality in oral health care. In order to make sure SNP receive the treatment they ought to receive, it is very important that SCD is taught and emphasized at the undergraduate level. Similar studies..$^{3,21}$ have shown that students who received exposure in treating SNP had positive experience and the exposure they received influenced their willingness to provide dental treatment to SNP.

SCD has been covered as an integrated module in the undergraduate curriculum for the last 2 academic years at University of Malaya. Students are exposed to examining, diagnosing and preparing treatment plan for the SNP. Since the last academic year, we run a dedicated SCD clinic under two specialists which the Yr5 students attend on a rotation basis. In addition, Yr4 students conduct a field visit to any one center for special needs like home for the aged or disabled, rehabilitation centers for physically and intellectually disabled or socially deprived. Since this academic year, Yr3 students undergo a Disability Equality Training (DET) workshop conducted by officials from the Ministry of Women, Family and Community Development. We intend to deliver the SCD curriculum using as many methods as possible because it has been reported that interactive multimedia, virtual patient learning modules with the help of case studies were very effective teaching methods. ${ }^{22}$ FYDO have better and more varied experience with SNP because during their government attachment they are posted to the public hospital where they obtain much hands-on experience. This should be emulated at the undergraduate level as well.

Research has shown that most dentists do not want to treat SNP because they find it stressful and challenging. ${ }^{23}$ Dao et al. rightly stated that 'the better the dentists had been educated about providing care for SNP, the better their attitudes were and the more likely they were to provide services for these patients'. ${ }^{24}$ Not all patients with disabilities require special care and general dental practitioners can treat majority of the patients with mild to moderate disabilities.

At present, there is no standardized method to compare dental schools in Malaysia with regard to the standards of competence required for SCD program. The Malaysian Qualifications Agency, which is a statutory body set up to accredit academic programs provided by educational institutions, need to look into new accreditation standards for SCD programs at undergraduate level. Future research should also focus on developing best practices for dental schools to eliminate oral health disparities and access to care issues for these patients.

\section{CONCLUSION}

Both group of respondents demonstrated minimum training and lack of confidence and skills that might contribute to a lack of preparedness in general dental practice to manage the oral health care needs of SNP. Clinical exposure in managing SNP at the undergraduate level is still inadequate and it needs to be emphasized in the curriculum. The higher education accreditation body needs to initiate development of standards of competence in managing SNP for undergraduate dental students.

\section{ACKNOWLEDGMENT}

Funding for this research was provided by the Ministry of Higher Education High Impact Research Grant [UM.C/HIR/MOHE/DENT/07]. 


\section{REFERENCES}

1. Anuar MK, Shukor AZ. Performance Study of Developed SMART EYE for Visually Impaired Person. Aust J Basic Appl Sci 2013:633-39.

2. WHO. The world health report 2002: reducing risks, promoting healthy life: World Health Organization; 2002.

3. Ahmad M, Razak I, Borromeo G. Special Needs Dentistry: perception, attitudes and educational experience of Malaysian dental students. Eur J Dent Educ 2015;19:44-52.

4. Yusuf MM. Women and pensions in Malaysia: assessing the impacts of disruptions in working life University of Southampton; 2012. United Kingdom.

5. Leonardi M, Bickenbach J, Ustun TB, Kostanjsek $\mathrm{N}$, Chatterji S, Consortium M. The definition of disability: what is in a name? Lancet 2006;368:121921.

6. Faulks D, Norderyd J, Molina G, Macgiolla Phadraig C, Scagnet G, Eschevins C, et al. Using the International Classification of Functioning, Disability and Health (ICF) to describe children referred to special care or paediatric dental services. PloS ONE 2013;8:e61993.

7. Gallagher J, Fiske J. Special care dentistry: a professional challenge. Br Dent J 2007;202:619-29.

8. Berk ML, Schur CL. The effect of fear on access to care among undocumented Latino immigrants. J Immigr Health 2001;3:151-56.

9. Krahn GL, Hammond L, Turner A. A cascade of disparities: health and health care access for people with intellectual disabilities. Ment Retard Dev Disabil Res Rev 2006;12:70-82.

10. Newacheck PW, Hung Y-Y, Wright KK. Racial and ethnic disparities in access to care for children with special health care needs.Ambul Pediatr 2002;2:24754.

11. Clemetson JC, Jones DL, Lacy ES, Hale D, Bolin KA. Preparing dental students to treat patients with special needs: Changes in predoctoral education after the revised accreditation standard. Eur J Dent Educ 2012;76:1457-65.

12. Waldman HB, Fenton SJ, Perlman SP, Cinotti DA. Preparing dental graduates to provide care to individuals with special needs. J Dent Educ 2005;69:249-54.
13. Schwenk DM, Stoeckel DC, Rieken SE. Survey of special patient care programs at US and Canadian dental schools. J Dent Educ 2007;71:1153-59.

14. Vainio L, Krause M, Inglehart MR. Patients with special needs: dental students' educational experiences, attitudes, and behavior. J Dent Educ 2011;75:13-22.

15. Krause M, Vainio L, Zwetchkenbaum S, Inglehart MR. Dental education about patients with special needs: a survey of US and Canadian dental schools. J Dent Educ. 2010;74:1179-89.

16. Bouhaimed M, Thalib L, Doi SA. Perception of the educational environment by medical students undergoing a curricular transition in Kuwait. Med Princ Pract 2009;18:204-8.

17. Horevoorts NJ, Vissers PA, Mols F, Thong MS, van de Poll-Franse LV. Response Rates for PatientReported Outcomes Using Web-Based Versus Paper Questionnaires: Comparison of Two Invitational Methods in Older Colorectal Cancer Patients. J Med Internet Res. 2015;17:e111.

18. Hohwü L, Lyshol H, Gissler M, Jonsson SH, Petzold M, Obel C. Web-based versus traditional paper questionnaires: a mixed-mode survey with a Nordic perspective. J Med Internet Res. 2013;15: e173.

19. Greig V, Sweeney P. Special care dentistry for general dental practice. Dent Update. 2012;40:4524, 456-458,4 60.

20. Shah AH, Cert P. Dentists and dental students opinion regarding dental treatment of patients with special needs. JPDA 2011;20:98-104.

21. Sherman CM, Anderson RD. Special needs education in Canadian dental school curriculum: is there Enough? J Can Dent Assoc. 2010;76:1-5.

22. Kleinert HL, Sanders C, Mink J, Nash D, Johnson J, Boyd S, et al. Improving student dentist competencies and perception of difficulty in delivering care to children with developmental disabilities using a virtual patient module. J Dent Educ 2007;71:279-86.

23. Faulks D, Freedman L, Thompson S, Sagheri D, Dougall A. The value of education in special care dentistry as a means of reducing inequalities in oral health. Eur J Dent Educ 2012;16:195-201.

24. Dao LP, Zwetchkenbaum S, Inglehart MR. General dentists and special needs patients: does dental education matter? J Dent Educ 2005;69:1107-15.

(Received August 29, 2015; Accepted October 26, 215) 